in this way those patients, usually middle-aged or older, who have a chronic fibrosing alveolitis of mural type; and those with extrinsic allergic alveolitis should be recognizable on a combination of clinical and immunological findings. The avoidance of the need for biopsy is a benefit that these patients can now enjoy, thanks to advances in medical knowledge derived in part from biopsies on earlier patients.

My sincerest thanks are due to Dr. K. F. W. Hinson, both for the instruction and pleasure I have derived from our discussions of clinicopathological correlations in lung disease over many years and for his help in the preparation of this lecture.

\section{REFERENCES}

Barboriak, J. J., Sosman, A. J., and Reed, C. E. (1965). fournal of Laboratory and Clinical Medicine, 65, 600.

Bergmann, M., et al. (1962). New England fournal of Medicine, 266, 750 .
Brunner, M. J., Giovacchini, R. P., Wyatt, J. P., Dunlap, F. E., and Calandra, J. C. (1963). Fournal of the American Medical Association, 184, 851 .

Churchill, E. D. (1951). New England 7ournal of Medicine, 245, 336.

Crofton, J., and Douglas, A. (1969). Respiratory Diseases. Oxford, Blackwell.

Gaensler, E. A., Hoffman, L., and Elliott, M. F. (1960). Poumon et le Coeur, 16, 1137

Gaensler, E. A., Moister, M. V. B., and Hamm, J. (1964). New England fournal of Medicine, 270, 1319

Hargreave, F. E., Pepys, J., Longbottom, J. L., and Wraith, D. G. (1966). Lancet 1, 445.

Liebow, A. A., Steer, A., and Billingsley, J. G. (1965). American fournal of Medicine, 39, 369 .

Pepys, J. (1967). Fournal of the Royal College of Physicians of London, $2,42$.

Pepys, J., et al. (1963). Lancet, 2, 607.

Pepys, J., Riddell, R. W., Citron, K. M., and Clayton, Y. M. (1962). Thorax, 17, 366 .

Scadding, J. G. (1958). Proceedings of the Royal Society of Medicine, 51,653 .

Scadding, J. G. (1964). British Medical fournal, 2, 686, 941.

Scadding, J. G. (1967a). Sarcoidosis. London, Eyre and Spottiswoode.

Scadding, J. G. (1967b). Lancet, 2, 877.

Scadding, J. G. (1968). Postgraduate Medical fournal, 44, 105.

Scadding, J. G. (1969). Proceedings of the Royal Society of Medicine, 62,227 .

Scadding, J. G., and Hinson, K. F. W. (1967). Thorax, 22, 291.

\title{
Haemostatic Mechanism in the Uterine Circulation during Placental Separation
}

\author{
JOHN BONNAR, ${ }^{*}$ M.B., CH.B., M.R.C.o.G. ; C. R. M. PRENTICE, $†$ M.B., B.CHIR., M.R.C.P. \\ G. P. MCNICOL, $\ddagger$ M.D., PH.D., F.R.C.P.(ED., GLASG.) ; A. S. DOUGLAS, $\square$ M.D., F.R.C.P.(LOND., ED., GLASG.)
}

\begin{abstract}
Summary: The haemostatic mechanism in the uterus $\checkmark$ during parturition was investigated in 12 patients being delivered by caesarean section. Detailed sequential study of the blood coagulation and fibrinolytic systems in the uterine circulation showed that placental separation is accompanied by a striking local activation of the clotting mechanism. Uterine vein blood draining the placental site while the placenta was separating showed a pronounced shortening of the whole-blood clotting-time, a significant shortening of other clotting-tests, and a sharp increase in factor VIII activity, though these changes were transitory. After delivery the level of fibrinogen and circulating platelets steadily increased and factor VIII activity remained high.

Activation of the clotting mechanism during placental separation appears to play an essential part in controlling uterine haemorrhage. The subsequent changes in the haemostatic mechanism in the puerperium are likely to predispose to thromboembolic complications.
\end{abstract}

\section{Introduction}

The physiological control of haemorrhage during parturition has been largely considered as a function of myometrial contraction. In a previous study (Bonnar et al., 1970) of normal childbirth changes in the peripheral blood were found which suggested that an activation of the clotting mechanism occurs during delivery. The present report gives the results of an investigation of the coagulation and fibrinolytic systems in the uterine circulation and simultaneously in the peripheral blood during and after placental separation at delivery by caesarean section.

\footnotetext{
* Present appointment: First Assistant, Nuffield Department of Obstetrics and Gynaecology, Radcliffe Infirmary, Oxford. † Senior Registrar in Medicine, University Department of Medicine,

$\ddagger$ Senior Lecturer, University Department of Medicine, Royal Infirmary, Glasgow C.4. $\S$ Professor of Medicine, University Department of Medicine, Royal
Infirmary, Glasgow C.4.
}

Placental separation presents an acute local challenge to the mechanisms responsible for the control of haemorrhage. The behaviour of the blood-clotting and fibrinolytic systems in the uterine circulation might theręfore be expected to reflect closely the events in the uterus during parturition.

\section{Patients and Methods}

Twelve patients with haemoglobin levels over $12 \mathrm{~g} . / 100 \mathrm{ml}$. were studied during and after delivery by elective caesarean section. Full consent was given by each patient for the blood samples to be taken as part of an investigation into the causes of haemorrhage during childbirth. After incision of the abdominal wall and exposure of the uterus, blood samples were taken simultaneously from a large vein on the surface of the uterus in the region of the placental site and from an arm vein. A lower uterine segment caesarean operation was then performed. Immediately after delivery of the baby blood samples were taken simultaneously from a vein at the uterine fundus draining the placental bed and from an arm vein. these specimens being obtained while the placenta was separating spontaneously in utero. The placenta was then delivered by gentle cord traction, and at intervals of 5 and 15 minutes after delivery of the placenta, blood samples were taken from veins draining the placental site and simultaneously from arm veins. On closure of the abdominal wall, about 25 minutes after placental delivery, a blood sample was taken from an arm vein. In the postoperative period peripheral blood samples were taken at 24 to 48 hours, 3 to 5 days, 6 to 9 days, and 10 to 14 days after operation. In a few instances blood samples were not obtained at all the times specified owing to the absence of an adequate number of suitable veins.

The blood samples $(16-18 \mathrm{ml}$.) were taken in every case by clean venepuncture into plastic syringes: $2 \mathrm{ml}$. was used for measuring the whole-blood clotting-time, $9 \mathrm{ml}$. was mixed with $1 \mathrm{ml}$. of $3.8 \%$ sodium citrate in a plastic tube for coagulation and fibrinolytic tests, $3-5 \mathrm{ml}$. was added to a plastic tube containing glass beads and $1 \mathrm{mg}$. of tranexamic acid for assay of fibrin/fibrinogen degradation products, and 
1-2 ml. was added to a plastic tube containing edetic acid for platelet counting. When blood samples were obtained at all the times specified the total quantity of blood removed amounted to $144 \mathrm{ml}$. during the operation and $80 \mathrm{ml}$. during the two weeks after operation.

The whole-blood clotting-time in plastic tubes was measured in the operating-theatre in a portable water-bath at $37^{\circ} \mathrm{C}$. by the method of Lee and White (1913) and the coagulation and fibrinolytic assays were performed within half an hour of collection of the blood, which was kept at $4^{\circ} \mathrm{C}$.

The following assays were performed:

Coagulation System Assays.-Recalcification time in plastic tubes (Biggs and Macfarlane, 1963). Kaolin-cephalin clottingtime (Proctor and Rapaport, 1961). Partial thromboplastin time (Langdell et al., 1963). One-stage prothrombin time (Douglas, 1962). Thrombin clotting-time (McNicol and Douglas, 1964) Factor V (Shanberge et al., 1967). Factors VIII and IX (Breckenridge and Ratnoff, 1962). Platelet count (Dacie and Lewis, 1963).

Fibrinolytic Enzyme System Assays.-Fibrinogen (Ratnoff and Menzie, 1964). Plasminogen (Remmert and Cohen, 1949). Euglobulin lysis activity (Nilsson and Olow, 1962). Urokinase sensitivity test (McNicol et al., 1965). Fibrin/fibrinogen degradation products (Bonnar et al., 1969a).

Statistical Analysis.-As the measurements were from a single group at different stages, Wilcoxon's Signed Ranks Test (Langley, 1968) was used to determine the statistical significance of any changes in the coagulation and fibrinolytic tests.

\section{Results}

\section{Coagulation System Assays}

The striking shortening of the whole-blood clotting-time and recalcification time in plastic tubes which was found in the uterine blood while the placenta was separating in utero is shown in Fig. 1. In two patients the blood sample taken

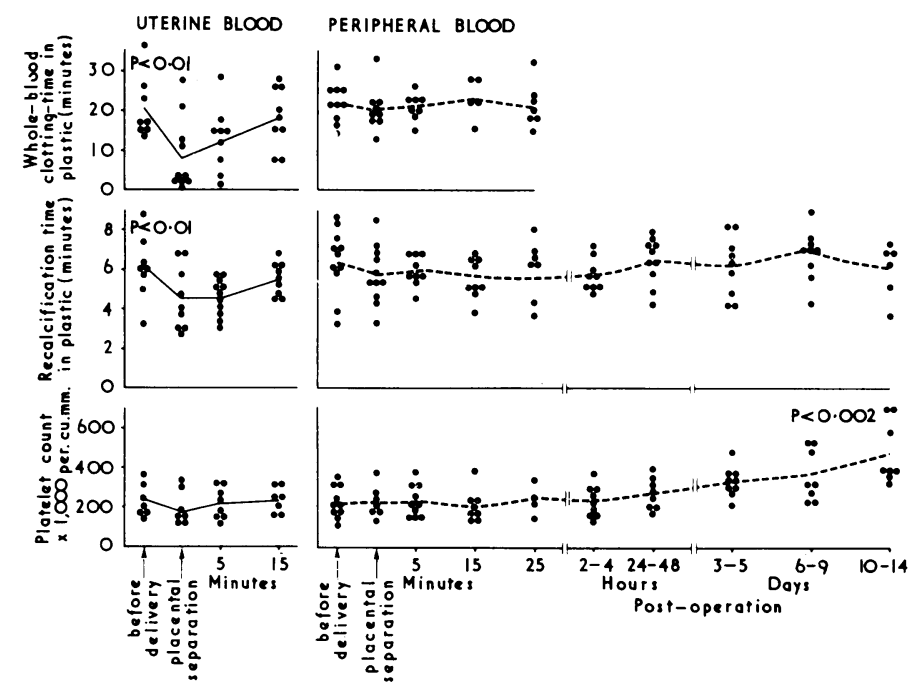

FIG. 1.-Whole-blood clotting-time and recalcification time in plastic and platelet count in uterine and peripheral venous blood during placental separation and after caesarean section.

from the uterine vein during placental separation clotted within seconds in the plastic syringe. The whole-blood clotting-time and recalcification time in the uterine vein blood during placental separation were significantly shorter than the times recorded in the peripheral blood taken simultaneously $(\mathrm{r}=0 ; \mathrm{P}<0.01)$. The shortening of the clotting-tests in uterine blood was a short-lived phenomenon lasting less than 15 minutes. During placental separation the platelet count in uterine blood decreased but no change was detected in peripheral blood. In the postoperative period a pronounced rise in the platelet count was found, the mean level steadily increasing from $229,000 / \mathrm{cu}$. $\mathrm{mm}$. at two to four hours after operation to $478,000 / \mathrm{cu}$. mm. at 10 to 14 days later.

During placental separation the shortening of the kaolincephalin clotting-time, partial thrmoboplastin time, and the one-stage prothrombin time was more pronounced in the uterine vein blood than in peripheral blood (Fig. 2). No significant change was found in the thrombin clotting-time in uterine or peripheral blood during or after placental separation.

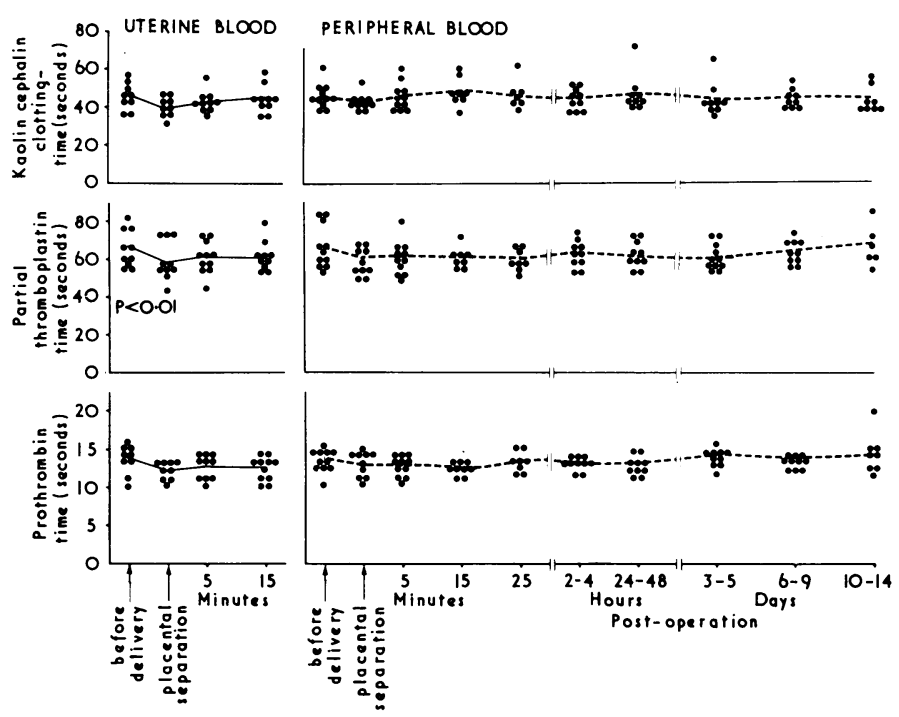

FIG. 2.-Kaolin-cephalin clotting-time, partial thromboplastin time, and prothrombin time during and after placental separation in uterine and peripheral venous blood.

The striking increase in factor VIII activity found in both uterine vein blood and peripheral blood during and after placental separation is shown in Fig. 3; the mean factor VIII activity in uterine blood rose from $141 \%$ before delivery to $336 \%$ during placental separation, and the simultaneous

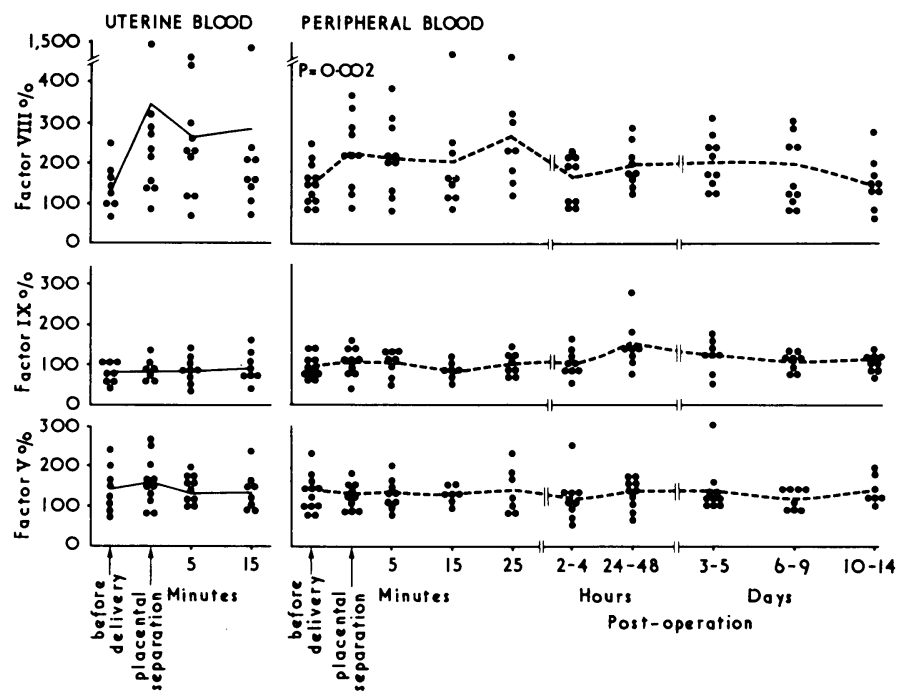

FIG. 3.-Factors VIII, IX, and V levels during and after placental separation in uterine and peripheral venous blood. 
samples of peripheral blood showed an increase from $148 \%$ before delivery to $228 \%$ during placental separation. Factor VIII activity, as shown in Fig. 3, remained raised in both uterine blood and peripheral blood following delivery of the placenta, but two to four hours after operation the mean factor VIII activity in peripheral blood had decreased to $155 \%$. In the two weeks following delivery by caesarean section the mean factor VIII activity was about $200 \%$, with a fall to $143 \%$ at 10 to 14 days after operation. No change was found in the level of factor IX or factor $\mathrm{V}$ in uterine or peripheral blood apart from a slight increase of factor IX activity 24 to 48 hours following delivery.

A significant negative correlation was present between the increase of factor VIII activity in uterine blood during and immediately after placental separation and the shortening at this time of both the kaolin-cephalin clotting-time $(\mathrm{r}=0.529 ; \mathrm{P}<0.01 ; \mathrm{y}=46.8-0.023 \mathrm{X})$ and the partial thromboplastin time $(r=0.589, \mathrm{P}<0.01 ; \mathrm{y}=71-0.048 \mathrm{X})$.

\section{Fibrinolytic Enzyme System Assays}

The decrease of the plasma fibrinogen level in the peripheral blood following the operation is shown in Fig. 4, the mean plasma level falling from about $400 \mathrm{mg}$. during the operation to $346 \mathrm{mg} . / 100 \mathrm{ml}$. two to four hours after. During the two weeks after delivery by caesarean section the plasma fibrinogen level progressively increased and the highest level was present at 10 to 14 days after the operation, when the mean level had risen to $536 \mathrm{mg} . / 100 \mathrm{ml}$. As shown in Fig. 4 the mean plasma plasminogen level decreased slightly in both uterine blood and peripheral blood following placental separation, and during the two weeks after the operation the mean plasminogen level remained virtually unchanged.
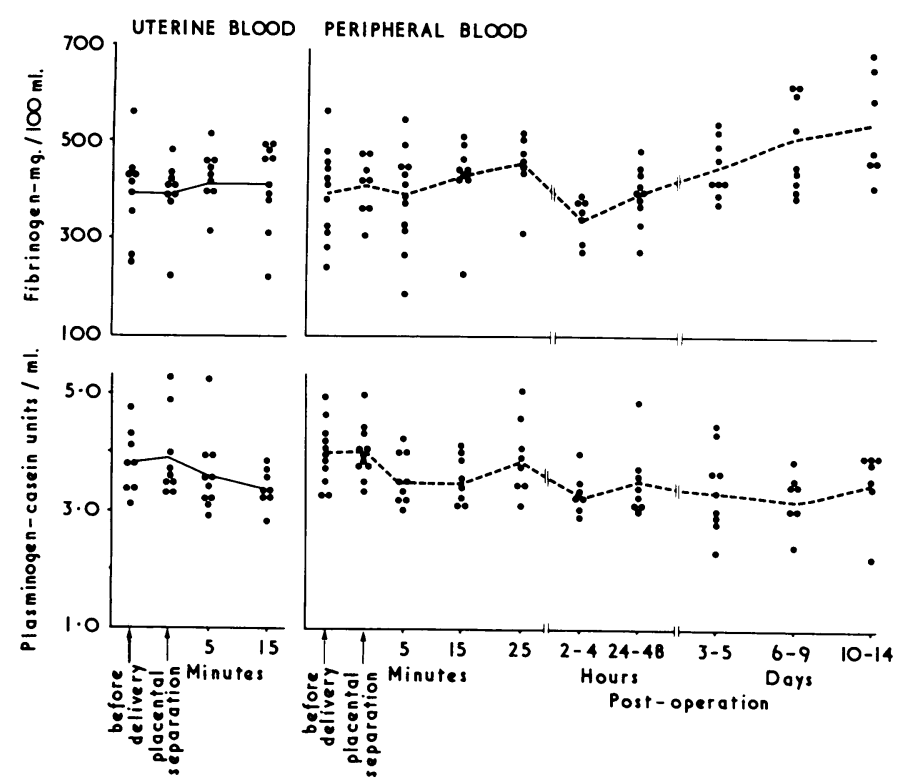

FIG. 4.-Fibrinogen and plasminogen levels during and after placental separation in uterine and peripheral venous blood.

The pronounced increase in the euglobulin lysis activity which was found in uterine blood during and immediately after placental separation is shown in Fig. 5, the level of activity being considerably higher than that recorded in the peripheral blood taken at the same time $(r=3, P<0.05)$. A pronounced inhibition of euglobulin lysis activity was present in the peripheral blood during and immediately after separation of the placenta, but at two to four hours after operation

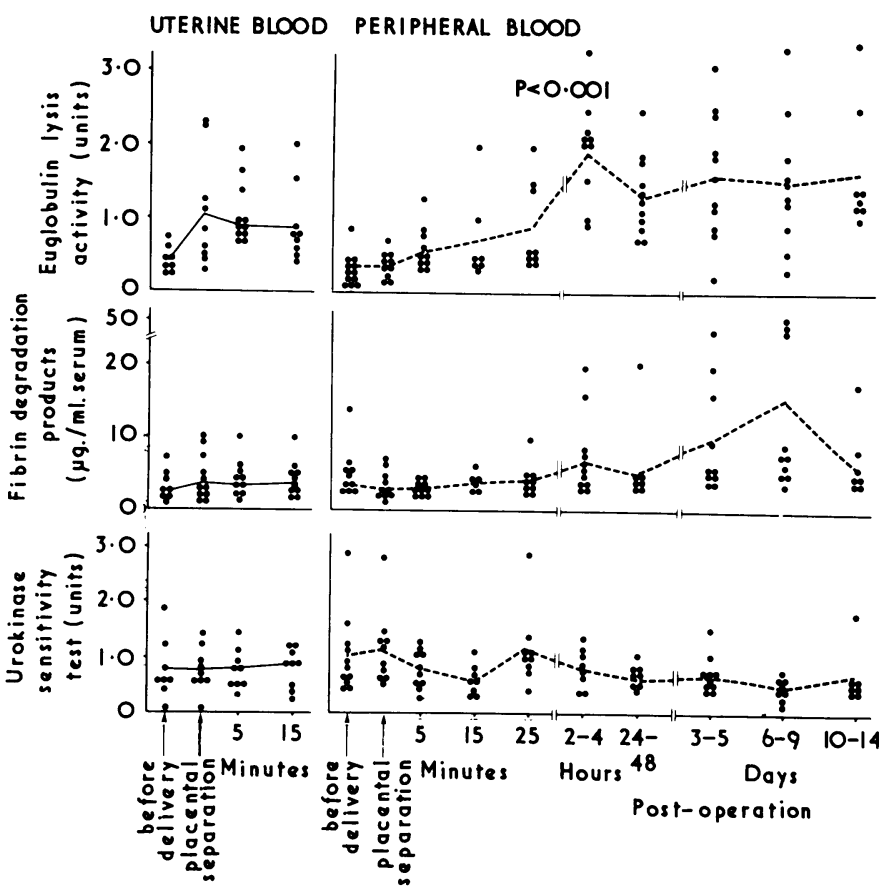

FIG. 5.-Fibrinolytic activity during and after placental separation in uterine and peripheral venous blood.

euglobulin lysis activity was in the normal non-pregnant range and remained so in the two weeks after operation. The level of fibrin/fibrinogen degradation products increased slightly in uterine blood during placental separation; in the peripheral blood the mean level increased from $3.53 \mu \mathrm{g} . / \mathrm{ml}$. at the end of the operation to $6.33 \mu \mathrm{g} . / \mathrm{ml}$. two to four hours later, and during the two weeks after operation a wide range of values was found, with peak levels at six to nine days after operation, when the mean value was $13.43 \mu \mathrm{g} . / \mathrm{ml}$. No change in the level of inhibitors to urokinase-induced lysis was detected in the uterine blood during or after placental separation, and in the peripheral blood the only change was a transient increase in the level of urokinase inhibition occurring immediately after placental separation.

\section{Discussion}

In normal circumstances blood-clotting takes place at sites of vascular injury. Our findings indicate that in the uterine circulation a distinct activation of the coagulation and fibrinolytic systems takes place during childbirth at the time of placental separation. The wide difference in activity between uterine blood and peripheral blood taken simultaneously indicates that in vivo a pronounced local activation of the clotting-mechanism may take place which produces only minimal changes in blood taken remote from the area involved. This was particularly evident in the shortening of the whole-blood clotting-time in plastic tubes during placental separation, when 6 of the 12 patients had clotting-times of three minutes or less in the uterine blood but only a slight shortening of the time took place in the peripheral blood. A similar but less pronounced pattern of results was also found in the recalcification time, kaolin-cephalin clotting-time, partial thromboplastin time, prothrombin time, and the platelet count.

A definite increase of factor VIII activity was found in uterine blood and to a lesser extent in peripheral blood during and immediately after placental separation, but the factor IX level remained virtually unchanged. The assay procedure for factor IX was identical to that for factor VIII except that the 
substrate plasma used was deficient in factor IX; the sharp increase in factor VIII activity cannot therefore be attributed to the presence of thromboplastin or some other nonspecific clotting accelerator which could influence the assay procedure. At the present time little is known of the detailed chemistry of the pathways of the blood-clotting mechanism. Recent studies (Özge-Anwar et al., 1965; Rapaport et al., 1965) have indicated, however, that when the coagulation sequence is activated the first traces of thrombin formed appear to act on factor VIII, producing a more reactive molecule which subsequently accelerates the intermediate phases of blood-clotting. The sudden increase of factor VIII activity in the uterine circulation may therefore be the result of thrombin formation due to the local release of tissue thromboplastin at the placental site.

Brown and Stalker (1969) showed in the hamster that thromboplastin material can enter the maternal and fetal circulation during placental separation. We have previously shown (Bonnar et al., 1970) that both transient shortening of clotting tests and increase of factor VIII activity take place in peripheral blood during placental separation at normal childbirth. The present studies would suggest that these changes are directly due to activation of the clottingmechanism in the uterine circulation producing to a lesser extent a coagulant effect in peripheral blood.

The potency of the mechanisms for keeping the clotting $\mathrm{o}^{f}$ blood a local phenomenon and clearing the activated clotting-factors from the circulation is shown by the fact th the pronounced changes in the uterine vein were transitory and had almost disappeared by the time the blood reached the peripheral circulation. This is probably why such a pronounced coagulant effect has not been noted previously during parturition. When studying changes in the haemostatic mechanisms caused by alterations in a single organ it seems important, therefore, to examine the blood directly leaving that organ, as the changes may not be detectable in the peripheral circulation. The plasma contains potent inhibitors of such factors as thrombin (Seegers and Marciniak, 1962) and activated factor X (Biggs et al., 1970), and activated clotting factors are apparently removed by the liver and the reticuloendothelial system (Spaet, 1962).

Fibrinolytic activity was reduced in both uterine blood and peripheral blood before delivery, but during placental separation the level of activity in the uterine blood was considerably increased compared with that in the peripheral blood-findings possibly due to plasminogen activator entering the circulation at the placental site. After delivery by caesarean section fibrinolytic activity in the peripheral blood followed a similar pattern to that found after normal vaginal delivery (Bonnar et al., 1970), the euglobulin lysis activity having returned to normal non-pregnant levels at two to four hours after operation.

The levels of fibrinogen, plasminogen, and factor VIII were decreased two to four hours after operation and at the same time levels of fibrin degradation products in the peripheral blood were increased. In the haemorrhagic complications of pregnancy, particularly abruptio placentae, much more striking changes, but in the same direction, have been found Verstraete et al., 1965; Bonnar et al., 1969b). Clearly, effective haemostasis in the uterus during placental separation places heavy demands on the coagulation factors, and the high levels found in normal pregnancy will provide a reserve of haemostatic components to meet this challenge.
The changes in the coagulation and fibrinolytic systems in the two weeks after caesarean section are of special interest as these may be aetiological factors involved in thromboembolic complications which may occur during this period. The raised factor VIII level and the progressive increase in the number of circulating platelets and in fibrinogen concentration over the two weeks after operation may be of particular importance in predisposition to thrombosis. Emmons and Mitchell (1965) reported that the maximum increase in both the to : platelet count and aggregation were present around the tenth postoperative day. The increase in the levels of fibrin degradation products, which was maximal at six to nine days after operation, could reflect lysis of intravascular fibrin deposits : this time. The changes of the haemostatic mechanism following caesarean section would appear to favour intravascular clotting, and such changes, together with the limited physical activity which of ten follows operative delivery, may explain the relatively high incidence of thromboembolic complications in the puerperium.

We are grateful to Sir Hector MacLennan and Professor E. M. McGirr for their interest in this work; to the Medical Research Council and to F.B.A. Pharmaceuticals Limited for financial assistance; and to Mrs. Christine Pidgeon, Mrs. Alison Sandiford, and Mrs. Eileen Cunningham for their expert laboratory assistance.

J.B. wishes to thank the Royal College of Obstetricians and Gynaecologists for the Samuel Research Scholarship which enabled him to carry out this work.

\section{REFERENCES}

Biggs, R., Denson, K. W. E., Akman, N., Borrett, R., and Haddon, M. E. (1970). British fournal of Haematology. In press.

Biggs, R., and Macfarlane, R. G. (1962). Human Blood Coagulation, 3rd edn., p. 384. Oxford, Blackwell.

Bonnar, J., Davidson, J. F., Pidgeon, C. F., McNicol, G. P., and Douglas, A. S. (1969a). British Medical fournal, 3, 137 .

Bonnar, J., McNicol, G. P., and Douglas, A. S. (1969b). Fournal of Obstetrics and Gynaecology of the British Commonwealth, 76, 799.

Bonnar, J., McNicol, G. P., and Douglas, A. S. (1970). British Medical Fournal, 2, 200

Breckenridge, R. T., and Ratnoff, O. D. (1962). Blood, 20, 137.

Brown, L. J., and Stalker, A. L. (1969). Microvascular Research, 1, 403. Dacie, J. V., and Lewis, S. M. (1963). Practical Haematology, 3rd edn. p. 61. London, Churchill.

Douglas, A. S. (1962). Anticoagulant Therapy, p. 279. Oxford, Blackwell. Emmons, P. R., and Mitchell, J. R. A. (1965). Lancet, 1, 71

Langdell, R. D., Wagner, R. H., and Brinkhous, K. M. (1963). Fournal of Laboratory and Clinical Medicine, 41, 637.

Langley, R. (1968). Practical Statistics for Non-Mathematical People, P. 181. London. Pan.

Lee, R. I., and White, P. D. (1913). American fournal of the Medical Sciences, 145, 495 .

McNicol, G. P., Barakat, A. A., and Douglas, A. S. (1965). Scottish Medical fournal, 10. 189

McNicol, G. P., and Douglas, A. S. (1964). In Recent Advances in Clinical Pathology, Series 4, ed. S. C. Dyke, p. 187. London, Churchill.

Nilsson, I. M., and Olow, B. (1962). Acta Chirurgica Scandinavica, 123, 247.

Ozge-Anwar, A. H., Connell, G. E., and Mustard, J. F. (1965). Blood, 26, 500 .

Proctor, R. R., and Rapaport, S. I. (1961). American fournal of Clinical Pathology, 36, 212.

Rapaport, S. I., Hjort, P. F., and Patch, M. J. (1965). Scandinavian fournal of Clinical and Laboratory Investigation, 17, Suppl. No. 84, p. 88.

Ratnoff, O. D., and Menzie, C. (1964). In Blood Coagulation, Hemorrhage and Thrombosis, L. M. Tocantins, and L. A. Kazal, p. 224. New York, Grune and Stratton.

Remmert, L. F., and Cohen, P. P. (1949). Journal of Biological Chemistry, 181, 431 .

Seegers, W. H., and Marciniak, E. (1962). Nature, 193, 1188.

Shanberge, J. N., Matsuoka. T., and Fukui, H. (1967). American fournal of Clinical Pathology, 47, 533.

Spaet, T. H. (1962). Thrombosis et Diathesis Haemorrhagica, 8, 276.

Verstraete, M., Vermylen, C., Vermylen, J., and Vandenbroucke, J. (1965). American fournal of Medicine, 38, 899. 